Sonja Kaufmann ${ }^{a}$, Mathis Lohaus ${ }^{b}$ (corresponding author)

${ }^{a}$ Hertie School of Governance, Friedrichstr. 180, 10117 Berlin, Germany; s.kaufmann@ @hertieschool.org

${ }^{b}$ University of Greifswald, Chair of International Relations, Baderstr. 6/7, 17489 Greifswald, Germany; mathis.lohaus@uni-greifswald.de

\title{
Ever closer or lost at sea? Scenarios for the future of transatlantic relations
}

\begin{abstract}
Five key drivers will shape the future of transatlantic relations in the next decade. Generally, the extent of shared liberal culture and European collective action capacity are crucial for cooperation between the EU and US. Additionally, it matters whether policymakers on both sides of the Atlantic agree on a conception of global order, on how to handle future technologies, and on the use of military force. Building on these drivers we develop and discuss four scenarios. The first describes a world of selective cooperation as the EU disintegrates. In the second, the US withdraws from the global stage and Europeans are forced to assume a leadership position. The third depicts negative consequences from populist nationalism, reducing transatlantic cooperation to military action against perceived Islamist threats. In the fourth scenario we focus on future technology that threatens to overwhelm transatlantic regulatory capacity.
\end{abstract}

Keywords: Scenarios, transatlantic relations, European Union, foreign policy, international relations

\section{Thinking about transatlantic relations in $\mathbf{2 0 2 5}$}

The transatlantic relationship has always involved questions about future trends and risks. However, the aftermath of Brexit and the US election in November 2016 has pushed uncertainty to a new level. Political goals and even shared principles appear to be up for renegotiation in the transition period from the Obama to the Trump administration. On the European side, the British vote to leave looms large, populism is on the rise across the board, and many citizens are still suffering from the ongoing economic and financial crises. Where do we go from here?

In the United States, the direction of foreign policy seems uncertain now that Donald Trump has won the Presidential elections (Jervis et al. 2017). Scenarios in many forms have been presented to make sense of what could be ahead in US foreign policy - and its meaning for the transatlantic relationship (see, for example, Ischinger 2016). At the time of writing, Trump's effect seems impossible to predict with any degree of confidence; and perhaps this caution is warranted considering that his electoral victory had been deemed next to impossible by geopolitical experts (Bremmer, Kupchan 2016, p. 23). The goal of this article, however, is to look beyond the immediate consequences of a new US administration. We focus here on trends and scenarios for the next decade of transatlantic relations. 
The scenarios discussed in this article reflect the discussions at a number of workshops held in Berlin in 2015 and 2016. Participants in these workshops - organized as part of the Dahrendorf Forum's foresight project - exchanged ideas about future EU relations with the United States, but also other key actors in the world (Sus, Pfeifer 2016). We followed the logic of multiple scenario generation (see Burrows and Gnad, this issue). First, the participants discussed basic assumptions about the nature of transatlantic relations. Second, under the guidance of the scenario facilitators we identified key drivers for the relationship between the two regions. As a third step, small working groups were formed to develop scenarios based on the most relevant pairs of key drivers identified in the plenary discussion. Finally, the most analytically interesting and policy-relevant scenarios were then selected by the whole group and developed further.

Transatlantic cooperation plays a key role in many arenas of global governance, such as the G7 and G20, the UN Security Council, and of course NATO. Together the United States and the European Union account for 12 per cent of the world population and roughly half of global (nominal) GDP as well as military expenditures. At the same time, there is a sense that the transatlantic dominance of world politics has peaked. Given the global economic and demographic trends as well as recent experiences of political disagreements, policymakers in the EU and US are well advised to think about priorities and pitfalls for future cooperation (Tocci, Alcaro 2012, pp. 2-9). Next to the electoral surprises of 2016, a number of indicators suggest trouble ahead: Negotiations about TTIP are at a standstill. The capabilities, financing and mission statement for NATO are unclear. And beyond such regional concerns, climate change and other global issues have made it abundantly clear that transatlantic cooperation and leadership are neither an automatism nor always sufficient to shape the global agenda in the twenty-first century.

Against this backdrop, we present and discuss four scenarios for the coming decade of transatlantic relations. These are not meant to comprehensively cover all possible outcomes. They rather represent a selection of important developments and policy implications. In the following section we discuss the key drivers identified by the participants of the scenario workshop. In the main part of the article we then present the resulting four scenarios: The first scenario sketches a mode of highly selective transatlantic cooperation; in the second, the EU reluctantly assumes a global leadership role; the third scenario focuses on the common perception of an external threat; the fourth addresses the consequences of transatlantic disagreement regarding technological innovation. We close with a brief discussion of common themes and implications.

\section{Key drivers for the future of transatlantic relations}

The workshop participants have identified a number of key drivers expected to influence EU relations with the United States over the next ten years. Conceptually, such drivers can be placed on a continuum between fundamentals and proximate causes. Demographics would be an example of the former: Major changes in the composition or size of populations are likely to shape policy choices. Electoral results, to pick an example mentioned in the previous section, can be thought of as a more immediate driver of change. The drivers chosen here are closer to the proximate than the fundamental end of the spectrum. This approach is sensible because we are interested in change over a ten-year period.

We focus on five key drivers. The first two are broad and subject to relatively slow change. Driver 1 concerns transatlantic liberal culture - that is, a shared understanding of political and societal values. Driver 2 addresses the cohesion among European member states - which is a precondition for EU 
collective action on the international stage. In addition, we consider three drivers that are more issue-specific and short-term. Driver 3 is concerned with conceptions of global order. Driver 4 regards the political management of future technology. Driver 5 , lastly, concerns agreement on the use of military force.

\subsection{Driver 1: Liberal transatlantic culture}

The US and Europe share a set of values that can be seen as the essential definition of Western societies. For a long time, Europe and the US have held a shared belief in individual freedoms, such as the freedom of speech, and transparent and accountable government (Welzel, Deutsch 2007, p. 250). The current surge of populist movements on both sides of the Atlantic takes aim at exactly those values (Buruma 2016). But not only changes in the political landscape shape how the common set of values develops. A range of sub-drivers-from demographics and society to political institutions and economy-determine the relationship.

History is an essential tie linking the two continents. Americans of European descent have valued, celebrated, and remembered their origins. But as the demographic composition changes and the ethnic makeup of the United States grows ever more diverse, European influences are less pronounced. On the other side, a young European generation, growing up in a unified, peaceful Europe, rather associates the US with tech companies and TV shows than with ending World War II and helping to establish democratic systems. Immigration in Europe is making societies more diverse and redirecting the focus to other regions in the world.

Another fundamental aspect of the transatlantic relationship is the liberal, parliamentary democracy as default political system. Today's Western models of governance assume that only a government that is established through free and fair elections and is accountable to its people can defend the individual freedoms and an open society. This might no longer hold true. In the latest wave of the World Values Survey, six per cent of Americans thought it was 'very good' and 28 per cent thought it was 'fairly good' to have a strong leader who is not bound by parliaments and elections (Foa, Mounk 2016). In Europe, a democratic malaise has taken hold and existing governance models are being questioned (Anheier 2017).

Overall, liberal culture is a key driver for transatlantic cooperation. At one end of the spectrum, both Americans and Europeans are deeply committed to a shared set of liberal values, leading to ever more integration between the two continents in political and economic issues. The other end is marked by authoritarian rule, populism, discrimination and the prosecution of minorities, and economic isolationism. Under such conditions, transatlantic cooperation no longer is a given.

\subsection{Driver 2: European capacity for collective action}

Thanks to the extensive institutional reforms in the treaty of Lisbon, the famous question about the European Union's 'phone number' is easier to answer today than in previous decades. The Commission and the European External Action Service - led by the High Representative - provide highly visible points of contact for foreign policy. In practice, however, these officials still depend on member states and the compatibility of their preferences. In the absence of coherent preferences or at least a permissive consensus among member states, the EU lacks capacity for collective action.

At the heart of this driver is the question of membership. For years the debate was more about which countries would be potential candidates for membership. After the United Kingdom's vote to leave the EU, the question rather seems to be how to keep the current members in the club. The way 
forward, it seems, can only be found through reforming the current EU governance (Pisany-Ferry 2016; Economist 2016; de Grauwe 2016). Brexit might also invigorate the EU's capacity for collective action, enabling closer collaboration on issues that have been off limits before, such as a Common Foreign and Security Policy or even a European Army.

Dynamics in domestic politics also shape cohesion at the EU level. As populists increase their antiBrussels rhetoric, collective action will be more difficult to organize at the European level. This challenge is most obvious when anti-European parties are in government, sending declared enemies of European governance as delegates to committees and agencies in Brussels. More than a decade after the Eastern enlargement, anti-European voices can be heard in many of the newer member states. But this trend is not limited to Eastern Europe. Anti-European political sentiments could force mainstream parties to take more careful positions in EU negotiations in an attempt to court moderately anti-European voters at home. There is some evidence to suggest that fringe parties have already contributed to a shift in the political agendas for governing parties in core member states (Meijers 2015).

Collective action capacity is at its highest when member states, or perhaps a sufficiently large coalition as part of multi-speed Europe, commit to deep and far-reaching cooperation. The low end of the spectrum, by contrast, is characterized by competing national interests, the unwillingness to pool resources, and a lack of coordination to reach strategic policy goals. A reduction of institutional competencies at the European level could further reduce collective action capacity.

\subsection{Driver 3: Global order}

As much as politicians and populist leaders want to make their voters believe: Countries do not exist in a vacuum, but in a highly interdependent world. Their opinion on how this world order should look shapes how governments behave on the international level. Foreign policy choices can range from isolationism to active engagement or even interventionism when governments attempt to shape the global order according to their ideals.

On a very basic level, the world order as we know it depends on governments' willingness to coordinate their behavior, share information, and cooperate with each other. To achieve their goals, countries enter into coalitions, as the US, EU, Russia, and China did for the Iran nuclear deal in 2015. Other manifestations of this behavior are international agreements, such as the Paris Agreement fighting climate change, and organizations such as the European Union itself. Of course governments can act unilaterally when it serves their geopolitical or strategic interests, as Russia has recently done in Crimea. Still, there is no denying the importance of international institutions and regimes, which have proliferated and expanded their scope in the past decades.

Next to the creation of institutions, governments' attitudes towards global order also shape their choice to (not) comply with international rules. International law, after all, cannot rely on a central enforcement authority. As the 1999 NATO intervention in Kosovo or the US-led invasion of Iraq in 2003 show, not all actors feel constrained by decisions of the UN Security Council. International institutions can also be paralyzed by diverging interests among their members, as in the case of the Syrian civil war since 2011. Finally, international organizations are dependent on governments for their funding, particularly as expanding mandates and new developments pose challenges.

Withholding or earmarking funds can be a way for governments to unilaterally pursue their interests. 
At the upper end of the spectrum for this driver, transatlantic partners support a multilateral world order. Relationships are based on international law and constructive cooperation in international organizations, whereas governments rarely try to circumvent or roll back their commitments. At the other extreme, the global order is fragmented. While the rules and norms embedded in the old institutions would persist on paper, the practice of global interactions would be much more anarchical and focused on ad-hoc bargaining for each issue.

\subsection{Driver 4: Future technology}

Technological developments are affecting the professional, private and political spheres of life. Political cooperation between the EU and US has often focused on fostering technological advancements, for instance through joint research projects or innovation-friendly regulatory politics. Both regions strive for technological leadership and an innovative business culture. Considering the speed and scale of technological change around the globe, the political response to future technology will be a key driver of transatlantic cooperation.

Business-led innovation has been hugely consequential in many areas. People around the globe are connected, resulting in new forms of work and leisure. New products spread to consumers in many markets simultaneously. Genetically modified organisms have the potential to fundamentally change agricultural production. Robotics and artificial intelligence (AI) are harbingers of even greater shifts in production and services. It seems certain that the distributional effects of technological change will increasingly feature in the political discourse on both sides of the Atlantic. It is up to governments to make choices about how to regulate private-sector innovation in a highly interdependent world.

In addition, the public sector itself is a producer of technology through research and development funding, is a consumer of civil and military innovations, and is affected by technological change. Access to information can be a blessing for public management and democratic participation - but also a curse for security and diplomacy. Technological breakthroughs in the security realm might inflate military spending as everyone attempts to keep up - or reduce it thanks to efficiency gains. Future technologies will offer transformational potential as well as new challenges.

At the positive end of the spectrum, transatlantic leadership on future technology results in the sharing of information, common and cross-fertilizing research agendas, and a climate of innovation in the private sector. In the opposite direction, access to information is abused, competition about innovation becomes adversarial, and policies regarding innovation are in opposition to each other and thus counterproductive.

\subsection{Driver 5: Military force}

In the aftermath of 9/11 it became evident that American and European decision-makers had different conceptions about the use of force. The US interventions in Afghanistan and Iraq were supported by some but not all European allies. Since then there have been heated debates about the appropriate course of action in Libya, Syria, Iran and elsewhere. While the United States have a long history of military interventions abroad, the EU is increasingly perceived as a security actor in its own right. In a world of globalized threats and uncertainty, doctrines about the use of military force will evolve and adapt - making them a key driver of transatlantic relations.

First and foremost, this is a matter of legitimacy concerns and strategic doctrines. Political decisionmakers can have widely different conceptions of the adequate balance between hard and soft power. Societal support for military action abroad has traditionally been much higher in the US than 
in Europe. However, in the aftermath of Iraq and Afghanistan it is easy to imagine a more isolationist stance taking hold. Among the EU member states, the willingness to employ soldiers and gear in other parts of the world varies significantly. Yet facing large-scale military conflict in the near abroad and terrorist threats at home, 'Venus' might decide to become more similar to 'Mars' after all (Kagan 2003).

At the same time, the EU's Common Security and Defense Policy concerns national sovereignty. The more resources are pooled, the more will their usage depend on the ability to reach consensus (see driver 2). Last but not least there is a huge financial and operational 'capability gap' between the US and EU. If the Europeans choose to play a more prominent role in global security, they need to increase their spending on, inter alia, air superiority, logistics and reconnaissance. As the debates about contributions to NATO have shown (Techau 2015), it is far from certain that European governments will aim for defense budgets anywhere close to what greater geopolitical ambitions would require.

The upper end of the spectrum is marked by a narrowing capabilities gap paired with converging transatlantic views on when and where using military force is legitimate and effective. This entails burden-sharing, pooled resources and coordinated strategies. At the other extreme, different cases of military conflict reveal that Americans and Europeans are unable to agree on the appropriate course of action, let alone a path to closing the gap in capabilities.

\section{Four scenarios to consider}

The four scenarios developed in this article cover a wide range of potential futures. They draw on earlier work done by the workshop participants (Kaufmann et al. 2016; Mann et al. 2016; Klavehn et al. 2016; Feyock et al. 2016). Liberal transatlantic culture and EU collective action capacity as fundamental drivers inform each scenario, defining the EU-US relationship. Different short-term drivers give each scenario a more issue-specific direction.

Table 1: Which drivers interact in which scenario?

\begin{tabular}{|c|c|c|c|c|c|}
\hline \multirow[t]{3}{*}{ Scenario } & \multicolumn{2}{|c|}{ Fundamental drivers } & \multirow{2}{*}{\multicolumn{3}{|c|}{$\begin{array}{l}\text { Short-term drivers } \\
\text { Agreement on... }\end{array}$}} \\
\hline & \multirow{2}{*}{$\begin{array}{l}\text { Liberal } \\
\text { transatlantic } \\
\text { culture }\end{array}$} & \multirow{2}{*}{$\begin{array}{l}\text { EU collective } \\
\text { Action } \\
\text { Capacity }\end{array}$} & & & \\
\hline & & & $\begin{array}{l}\text { International } \\
\text { order }\end{array}$ & $\begin{array}{l}\text { Future } \\
\text { technology }\end{array}$ & $\begin{array}{l}\text { Use of } \\
\text { military } \\
\text { force }\end{array}$ \\
\hline Pick and choose & + & - & + & & \\
\hline Europe takes the wheel & - & + & - & & \\
\hline Rally 'round the flag & - & - & & & + \\
\hline Rules for the future & - & - & & - & \\
\hline
\end{tabular}

\subsection{Scenario 1: Pick and choose}

If Europe disintegrates, does this spell the end for transatlantic cooperation? Not necessarily! In this scenario, political leaders on both sides of the Atlantic continue to respect liberal values and emphasize international engagement. Yet as they deem the project of ever-closer integration to be damaged beyond repair, governments abandon collective foreign policy and instead opt for a pragmatic pick-and-choose approach. The end of the EU as we know it is not necessarily bad for transatlantic relations. 
At the beginning of 2016, both Brexit and Donald Trump's electoral success seemed very unlikely, yet both events came true. In Europe, this triggers renewed efforts to improve democratic governance, including a debate about reforming the EU. After all, the perceived lack of democratic legitimacy has been a driving factor in the rise of populism. Many governments fear to lose power to populistnationalist parties in upcoming elections, considering that the economic situation in Europe is still problematic. Struggling economies play with the idea of leaving the Eurozone, which leads to another debate about the feasibility of the common currency. In an effort to counter critics, EU leaders agree to revisit the Union's institutional architecture. Yet they prove unable to reach consensus on controversial issues such as the distribution of refugees. As Europe is preoccupied with its internal governance issues and the US under president Trump retreat from the international stage, transatlantic relations are reduced to the basics.

The relationship warms again when Trump loses reelection and a more moderate US administration renews the US commitment to its international responsibilities and allies. Proponents of strong transatlantic cooperation breathe a sigh of relief. Meanwhile, however, EU governance is facing a severe crisis. After another economic downturn, Spain and Italy decide to leave the Eurozone, marking the end of the common currency. As a consequence, the economic troubles spread to export-focused economies, most notably Germany. Continuing disagreements about border management and welfare payments result in the suspension of the Schengen agreement, unwinding a fundamental element of EU integration. Plans to further integrate foreign and security policy are put on ice in the face of such fundamental problems. As a restart of TTIP seems out of the question, the US concludes a bilateral trade deal with the UK, prompting others to make similar plans. Without a coherent joint strategy on issues such as trade or foreign and security policy, the EU loses its appeal as a partner. As a consequence, the US pursues stronger bilateral ties with strategically important individual countries.

Eventually, the EU is hollowed out and no longer functions as a collective. Instead, a Europe of multiple speeds and selective integration emerges. States collaborate informally on different issue areas. When it comes to global governance, European governments act within the United Nations or, if they can, the G20 or G7. Peripheral EU member states lose relevance in the absence of a shared foreign policy framework. Yet given the traumatic experience of disintegration, a formal consolidation of foreign policy is not on the agenda anytime soon. The transatlantic relationship is thus characterized by a high degree of selectivity, as a small group of allies cooperates on a range of topics. Paradoxically, this informal network of transatlantic partners might be able to pursue ambitious foreign policy goals more effectively than before.

Two major indicators are relevant for this scenario. First, the current trend towards isolationism should subside relatively soon. Instead, leaders in the EU and US are expected to emphasize their willingness to take on international responsibilities. The other telltale sign would be the breakdown of core aspects of European integration and their replacement by informal, issue-specific groups.

\subsection{Scenario 2: Europe takes the wheel}

The decline of American hegemony has been proclaimed many times, but the US has continued to be the sole superpower on the block. Yet the 2016 election might go down in history as the turning point - if the new administration follows through with its plan to put 'America First' and withdraws from international responsibilities. This policy change puts European collective action capacity to a test, leaving the EU to carry on the torch of liberal values and democracy in the global world order. 
Following the Brexit shock, EU leaders agree on a communications and legitimacy offensive to fend off populist movements in the wake of Brexit. Europe's foreign policy apparatus evolves. As the EEAS gains experience and fine-tunes its working relationship with member states and the EU Commission, the changes intended by the Lisbon treaty begin to materialize in practical terms. The center of gravity for day-to-day foreign policy moves to the European level, not least because EU members are happy to consolidate expensive foreign operations. At the same time, the United States decrease their footprint in terms of both diplomatic and military capabilities abroad. US foreign policy focuses on core regions and tasks, which means cutting back on large-scale diplomatic initiatives, early warning and conflict resolution, or intelligence analysis. These policy shifts draw heavy criticism from European allies and the transatlantic relationship suffers - also because the new US administration uses a different tone and style towards the old allies.

These organizational and strategic changes are reflected in policy choices. In United Nations negotiations on climate change, the EU is the only actor that comes close to China's willingness and capacity for leadership. Participants in transatlantic working groups discover that their goals are not aligned. In addition, US negotiators are much less enthusiastic about investing political capital and resources in global governance. UN operational budgets across the board are sharply reduced reflecting a reduction in US contributions that cannot be compensated by others. Thus, while the UN remains a forum for deliberation, its agencies lose practical relevance in global governance. At the same time, the member states of the European Union come to terms with the fact that their transatlantic partner seems less willing to assume a leadership role. A number of governments and the foreign-policy institutions in Brussels take on more responsibility in regional and global affairs.

As a result, EU policymakers focus more heavily on inter-regional cooperation with organizations from Africa, Latin America and Asia. A number of so-called 'intensive partnership' treaties with regional blocs and individual emerging powers address cross-border issues, such as migration and the fight against crime. In trade and investment, regional arrangements increasingly replace the WTO, which is in hibernation due to the United States' refusal to champion further trade liberalization on a global scale. NATO suffers from funding cuts and is strictly limited to its core mandate for territorial defense, while the UN Security Council drops from gridlock to paralysis. Military interventions still take place - but only based on ad-hoc coalitions. For the EU this means creating a more deeply integrated but still voluntary defense framework with a focus on security in the near abroad and African countries of strategic interest.

A first indicator for this scenario is a shift in US foreign policy from a global leadership role to a few selected initiatives. American agenda-setting power on the global stage is reduced as foreign-policy priorities change, but also because European allies in turn focus on other partners and opportunities. EU-internal changes in the institutional setup and practice of foreign policy are another indicator to consider. The clearest sign of this scenario, however, would be bolder and more controversial European actions on the global arena - both diplomatically and militarily.

\subsection{Scenario 3: Rally 'round the flag}

With populist nationalism on the rise on both sides of the Atlantic, one could expect that governments focus on isolationism and, in the European case, dismantling supranational structures. This is not necessarily the case. Instead, they might find a common enemy to fight, which could even lead to unprecedented cooperation. In this scenario, populist leaders in the US and throughout Europe declare a war against Islamic extremism, which they see as the central threat to the West. 
Next to ideological motivations, this can be seen as strategic behavior to gain support from constituents and to divert attention away from economic hardships.

Donald Trump's victory was only the beginning of a populist turn in world politics. Several European countries choose or get very close to electing populist leaders. Even when mainstream parties remain in power, this populist trend affects the political discourse. Narratives of fear and xenophobia go hand in hand with the discrimination of minorities. In Europe, Brexit leaves a gap in terms of capacity and funding. Several other states with strong populist movements discuss leaving the EU as well, hoping to get 'better deals' or renegotiate parts of the EU institutional system. The uncertainty about how international trade will be affected leads to a downturn of economic growth, especially in export-depending economies like Germany. Following the populist logic of putting their own people first, the US government establishes a modified version of the isolationist Monroe doctrine and withdraws from combat zones. Others follow this example, thus further destabilizing some world regions. Ironically, this withdrawal - paired with inaction regarding new conflicts elsewhere - leads to increased refugee streams from the Middle East and Northern Africa. Transatlantic relations in this period are largely limited to populist leaders assuring each other and rejecting more interventionist or liberal positions.

Following these developments, central pillars of the EU - such as the single market, open borders, the Dublin system on refugees, or the Euro currency - are renegotiated or even abandoned. Populists gain power in more countries and decide to re-nationalize essential tasks such as border management and foreign policy. Many member state delegates in Brussels no longer seek to work on European integration, but rather want to keep suspicious EU bodies in check. As a result, the institutional setup of the EU is hollowed out and its collective action capacity sharply diminished. In reaction to the reversal of European integration in trade policy, the US reverts to bilateral agreements favoring like-minded countries. As the Europeans and the US increasingly retreat from the international stage both militarily and diplomatically, other states and regional blocs are stepping up. Transatlantic relations are at a low point.

Economically, populist policies soon reach their limits, as bringing back jobs despite technological changes proves impossible. Trade and investment flows decline sharply due to protectionism and retaliatory sanctions from other nations. At the same time, social tensions on the continent grow. Refugee camps become hotspots of crime and extremism - ultimately leading to a vicious cycle of violence and repression. In this heated political climate, terrorist attacks in Europe then act as triggers to further tighten security laws also in the United States. Populist leaders, particularly those with right-wing ideologies, are quick to single out refugees and minorities as political scapegoats. After several steps of escalation they finally decide to declare war on their perceived enemies. A transatlantic coalition of the willing invades one or multiple countries with a Muslim majority, which they see as the origin of Islamist extremism and terrorism. In the name of defending the 'West' against Islamist threats, NATO or a different military alliance is bolstered. Conveniently for populist leaders, such military adventures abroad also help to bolster domestic support due to a 'rally around the flag' effect (Lian, Oneal 1993).

Several indicators would point to the realization of this scenario. First, populist nationalism should continue to be strong in elections in Europe and the US despite a failure to fulfill economic promises. The continued dominance of nationalist, extreme and discriminatory rhetoric after populist leaders take office would be another indicator: Escalation could be avoided if societal actors, or perhaps the 
populists themselves, take more moderate positions. A final sign to look out for is an increase in violence by terrorists - which act as catalysts in this scenario - and governments.

\subsection{Scenario 4: Rules for the future}

Genetically modified organisms (GMOs); artificial intelligence; autonomous weapons systems; 3Dprinting; electronic surveillance and attack systems; nano-scale robotics. These keywords illustrate how real-world technology has caught up to science fiction in many areas. Political decision-makers on both sides of the Atlantic, however, lack a strategic vision of how to regulate cutting-edge technologies. Without a clear set of shared rules, the genie of mass surveillance - to name just one example - is impossible to put back into the bottle.

Blindsided by the speed and magnitude of technological change, politicians and bureaucrats are slowly beginning to react to regulatory challenges. Technological progress in key areas such as autonomous weaponry and GMOs is already highly politicized. On both sides of the Atlantic, politicians attempt to balance broad societal concerns with business interests. Yet transatlantic leaders fail to jointly address the implications of private-sector innovation, let alone make an effort to coordinate research and development in the defense sector. Piecemeal solutions might allow politicians to address voters' immediate concerns. In the long run, however, regulatory differences create an uneven playing field, and the pressure keeps mounting with every far-reaching innovation.

In the United States, the federal government takes a laissez-faire position on private-sector innovation. Military research intensifies as Pentagon officials draw positive conclusions from pilot programs with autonomous drones and a toolkit to enhance offensive cyber capabilities. They are reluctant to share advanced technology with NATO partners due to concerns about Russian and Chinese spying. In Europe, by contrast, high-level politicians increasingly point to risks associated with new technologies. Opinion polls show that voters are worried about health and security questions related to genetically modified organisms and artificial intelligence. On the labor market, advances in robotics show their disruptive potential. Genetically modified crops provided by an American conglomerate turn out to have unintended side effects on the environment. EU officials also voice concerns with regard to the privacy of European citizens, whose data is being mined and used for targeted political advertising on social media platforms hosted in the US and the UK. An outbreak of avian influenza in continental Europe, meanwhile, leads to a US ban on meat and livestock imports as well as quarantine rules for European travelers from multiple countries.

In response to public concerns about these issues, the high-level transatlantic technology council (TTC) convenes for its inaugural meeting. Modeled after an earlier initiative on economic cooperation, the body aims to enhance cooperation and trust by changing the highly balkanized and inefficient landscape of technology regulation. After long rounds of negotiations the experts publish a non-binding whitepaper regarding nano-scale robotics in the health sector. Military usage of these robots remains a possibility as a European proposal for a moratorium is removed from the final communiqué at the last minute. Another exception concerns ongoing US-Chinese joint ventures, which are in conflict with EU medical ethics rules. Participants are quick to call the TTC a political success, but in the absence of concrete results the forum fails to become relevant. As EU and US negotiators are unable to overcome conflicts regarding broad societal values as well as concrete technical standards, the future of transatlantic economic and security cooperation looks doubtful. 
Three sets of indicators matter for this scenario. Observers should watch for the framing of technology in political discourse: Future technology is bound to be painted as a huge risk by some while others will warn against over-regulation. This is linked to economic policy. Economies of scale and winner-takes-it-all dynamics could tempt politicians to pursue policies of economic nationalism, trying to prop up and protect national champions. Lastly, the incidence of industrial espionage and mutual mistrust will greatly influence the chances for meaningful transatlantic cooperation.

\section{Where do we go from here?}

2016 has been a year of unexpected events. At the time of writing, both Brexit and the Trump presidency pose unprecedented challenges and uncertainties. Researchers and practitioners interested in transatlantic relations are well-advised to be humble about their ability to predict the consequences. In such an uncertain context, scenario generation is a valuable tool to structure thoughts and expectations. By identifying key drivers, we are able to focus our attention on politically relevant trends. There is no doubt that liberal transatlantic culture and European collective action capacity will be important to watch. In addition, we propose three more issue-specific drivers of transatlantic relations: Preferences about global order, the regulation of future technology, and consensus about the use of military force. These are not independent of the first two. Nonetheless, spelling out these drivers in more detail helps to focus the analysis.

Building on the key drivers, we have discussed four scenarios. In the world of pick and choose, the transatlantic relationship is reduced to selected policy initiatives in the face of European disintegration. Europe takes the wheel paints a picture of US disengagement that leads to the EU assuming a global leadership role. Given the unresolved financial and migration crises in Europe and the surge of populism on both sides of the Atlantic, these two scenarios seem entirely within the realm of possibility. They further illustrate that liberal culture and EU collective action capacity do not necessarily move in tandem. The third and fourth scenarios are concerned with less benign outcomes. Rally 'round the flag depicts a world in which populist nationalism leads to large-scale violence in Europe and abroad, as military force is the only policy initiative uniting transatlantic leaders. We urge readers to carefully assess how likely they find this worst-case scenario - keeping in mind the recent political surprises and the permanent uncertainty associated with terrorism (Hegghammer 2016). In rules for the future, last but not least, we make the case that transatlantic relations will not sustain themselves without concrete, collaborative efforts to update and adapt the rules of the game.

We hope that our key drivers and scenarios encourage readers to consider some issues of transatlantic cooperation that were below the radar before. The process of scenario generation itself has shown how volatile and difficult to predict even a historically stable set of international relations can be. In such a climate of uncertainty, this discussion offers two concrete benefits. First, the indicators associated with key drivers and scenarios serve as an early-warning system. Experimental research has shown some success in forecasting the development of key variables in an effort to assign probabilities to geopolitical events (Mellers et al. 2015; Tetlock, Gardner 2015). By identifying key drivers and indicators, scenario generation can be a useful starting point for these endeavors. ${ }^{1}$

Second, scenarios are meant to spur the discussion of contingency plans. Future scenario generation is helpful only if present practitioners consider their options in case unfavorable conditions emerge

\footnotetext{
${ }^{1}$ Full disclosure: The corresponding author is a participant in the "Good Judgment" forecasting exercise.
} 
(cf. Sardar 2010, p. 184).The European Commission itself has just conducted a scenario exercise and presented five possible futures for the Union after Brexit (European Commission 2017). Clearly, different degrees of transatlantic cooperation are possible depending on the configuration of key drivers. If the European Union has the ambition to be a key player on the global stage in 2025 and beyond, decision-makers must consider how to reach a productive consensus with their American partners. Picking and choosing could be sensible if broad agreements prove elusive. At the same time, it seems wise to prepare for a world with much less US guidance and leadership. This will require decisions that go beyond the EU's 2016 Global Strategy, which offers just a few sentences on transatlantic relations:

"With the US, the EU will strive for a Transatlantic Trade and Investment Partnership (TTIP). Like the Comprehensive Economic and Trade Agreement (CETA) with Canada, TTIP demonstrates the transatlantic commitment to shared values and signals our willingness to pursue an ambitious rules-based trade agenda. On the broader security agenda, the US will continue to be our core partner. The EU will deepen cooperation with the US and Canada on crisis management, counter-terrorism, cyber, migration, energy and climate action." (European Union 2016, p. 37)

At the time of writing, TTIP seems implausible and 'shared values' might no longer be a given either. First impressions of President Trump's foreign policy suggest that he might channel Nixon's 'madman' theory and do away with the conventional playbook of diplomatic traditions (Kirchick 2016).

Even if those worries turn out to be unfounded: Considering the deep uncertainty regarding all key drivers, now is the time for EU leaders to define more concrete policy priorities and publicly commit to them. How should transatlantic security cooperation evolve? Under which conditions and to what end should the transatlantic integration of trade, investment, migration and other interactions be reinvigorated? What are European priorities and principles in multilateral forums and regarding global issues? Establishing more concrete positions will be time-consuming and politically costly because member states have to reach agreement. It also means taking risks, as some aspects might antagonize transatlantic partners. But the uncertainty about American policy in coming years is a crucial window of opportunity for the EU to draft a common foreign and security policy that really deserves this label. If European leaders fail to clearly communicate their priorities and shape the agenda, they will find themselves trying to correct the course set by others, or by accident. 


\section{Acknowledgments}

Monika Sus and Franziska Pfeifer organized the scenario workshops in Berlin. Randy Pherson and Oliver Gnad facilitated the scenario generation. While we draw heavily on the output of all workshop participants, the errors made and opinions expressed in this article are ours. Many thanks to everyone involved!

\section{References}

Anheier, Helmut K. (2017): Democracy Challenged. In Hertie School of Governance (Ed.): The Governance Report 2017. Oxford: Oxford University Press, pp. 13-20.

Bremmer, Ian; Kupchan, Cliff (2016): Top Risks 2016. Eurasia Group. New York. Available online at http://www.eurasiagroup.net/siteFiles/Issues/1512 Top Risks 2016.pdf, checked on 11/18/2016.

Buruma, Ian (2016): The End of the Anglo-American Order. In The New York Times, 11/29/2016. Available online at http://nyti.ms/2gDAv47, checked on 11/29/2016.

de Grauwe, Paul (2016): What Future for the EU After Brexit? In Intereconomics 51 (5), pp. 249-251. DOI: 10.1007/s10272-016-0612-0.

Economist (2016): The future of the EU: Now what? In The Economist, 9/3/2016. Available online at http://www.economist.com/news/europe/21706284-europe-vows-progress-after-brexit-unsurewhich-way-go-now-what, checked on 11/29/2016.

European Commission (2017): European Commission (2017): White Paper on the Future of Europe. Reflections and scenarios for the EU27 by 2025. COM(2017)2025. European Union. Brussels. DOI: $10.2775 / 32364$.

European Union (2016): Shared Vision, Common Action. A Stronger Europe A Global Strategy for the European Union's Foreign And Security Policy. Brussels. Available online at http://europa.eu/globalstrategy/en, checked on 12/21/2016.

Feyock, Sebastian; Garrett, Crister; Lohaus, Mathis (2016): The 'transatlantic Frankenstein'. In Monika Sus, Franziska Pfeifer (Eds.): European Union in the World 2025. Scenarios for EU relations with its neighbours and strategic partners. Hertie School of Governance and LSE Ideas: Dahrendorf Analysis May 2016, pp. 9-12.

Foa, Roberto Stefan; Mounk, Yasha (2016): The Democratic Disconnect. In Journal of Democracy 27 (3), pp. 5-17.

Hegghammer, Thomas (2016): The Future of Jihadism in Europe: A Pessimistic View. In Perspectives on Terrorism 10 (6), pp. 156-170.

Ischinger, Wolfgang (2016): What Europe Needs to Hear from Trump. In The New York Times, 11/11/2016. Available online at http://nyti.ms/2eLP3xl, checked on 11/18/2016.

Jervis, Robert; Busby, Joshua W.; Monten, Jonathan; Chaudoin, Stephen; Milner, Helen V.; Tingley, Dustin et al. (2017): ISSF Policy Roundtable 1-6: Is Liberal Internationalism Still Alive? International Security Studies Forum. Available online at http://issforum.org/roundtables/policy/1-6-liberalinternationalism, checked on 3/30/2017. 
Kagan, Robert (2003): Paradise and power: America and Europe in the New World Order. London: Atlantic Books.

Kaufmann, Sonja; Rieck Moncayo, Gunter; Ringleb, Lena; Thunert, Martin (2016): Dinner à la carte. In Monika Sus, Franziska Pfeifer (Eds.): European Union in the World 2025. Scenarios for EU relations with its neighbours and strategic partners. Hertie School of Governance and LSE Ideas: Dahrendorf Analysis May 2016, pp. 7-9.

Kirchick, James (2016): Trump's 'Madman' Foreign Policy Strategy. Voice of America. Available online at http://blogs.voanews.com/us-opinion/2016/05/10/trumps-madman-foreign-policy-strategy/, checked on $12 / 22 / 2016$.

Klavehn, Christoph; Krug, Laura; Puglierin, Jana (2016): Inventing the enemy. In Monika Sus, Franziska Pfeifer (Eds.): European Union in the World 2025. Scenarios for EU relations with its neighbours and strategic partners. Hertie School of Governance and LSE Ideas: Dahrendorf Analysis May 2016, pp. 13-15.

Lian, Bradley; Oneal, John R. (1993): Presidents, the Use of Military Force, and Public Opinion. In The Journal of Conflict Resolution 37 (2), pp. 277-300.

Mann, Dennis-Jonathan; Thimm, Johannes; Viola, Laura Anne (2016): EU hegemony by default. In Monika Sus, Franziska Pfeifer (Eds.): European Union in the World 2025. Scenarios for EU relations with its neighbours and strategic partners. Hertie School of Governance and LSE Ideas: Dahrendorf Analysis May 2016, pp. 5-6.

Meijers, Maurits J. (2015): Contagious Euroscepticism. The impact of Eurosceptic support on mainstream party positions on European integration. In Party Politics. DOI:

$10.1177 / 1354068815601787$.

Mellers, Barbara; Stone, Eric; Murray, Terry; Minster, Angela; Rohrbaugh, Nick; Bishop, Michael et al. (2015): Identifying and cultivating superforecasters as a method of improving probabilistic predictions. In Perspectives on psychological science : a journal of the Association for Psychological Science 10 (3), pp. 267-281. DOI: 10.1177/1745691615577794.

Pisany-Ferry, Jean (2016): Brexit and the Future of Europe. In Project Syndicate, 8/31/2016. Available online at https://www.project-syndicate.org/commentary/brexit-future-of-europe-by-jean-pisaniferry-2016-08, checked on 11/29/2016.

Sardar, Ziauddin (2010): The Namesake. Futures; futures studies; futurology; futuristic; foresightWhat's in a name? In Futures 42 (3), pp. 177-184. DOI: 10.1016/j.futures.2009.11.001.

Sus, Monika; Pfeifer, Franziska (Eds.) (2016): European Union in the World 2025. Scenarios for EU relations with its neighbours and strategic partners. Hertie School of Governance and LSE Ideas: Dahrendorf Analysis May 2016. Available online at http://www.dahrendorfforum.eu/publications/european-union-in-the-world-2025-scenarios-for-eu-relations/, checked on $11 / 18 / 2016$.

Techau, Jan (2015): The Politics of 2 Percent. NATO and the Security Vacuum in Europe. Carnegie Endowment for International Peace. Washington, D.C. Available online at http://carnegieendowment.org/files/CP 252 Techau NATO Final.pdf, checked on 3/30/2017.

Tetlock, Philip; Gardner, Dan (2015): Superforecasting: The Art and Science of Prediction. New York: Crown Publishers. 
Tocci, Nathalie; Alcaro, Riccardo (2012): Three Scenarios for the Future of the Transatlantic Relationship (Transworld Working Paper, 04). Available online at http://www.transworldfp7.eu/?p=669, checked on 11/18/2016.

Welzel, Christian Peter; Deutsch, Franziska (2007): Value patterns in Europe and the United States: is there a transatlantic rift? In Helmut K. Anheier, Yudhishthir Raj Isar (Eds.): Conflicts and Tensions. Los Angeles: SAGE (The Cultures and Globalization Series, 1), pp. 241-252. 